two days thrice a day ; the sixth day it was used only once, and then discontinued because the patient felt dizzy and complained of dryness of the mouth.

CASE 7.-J. E-, aged thirty-six, male, had traumatic cataract of some years' standing. Duboisin was used for examination. The patient said it made him feel "tipsy," and he became very pale and could not walk straight. No tendency to delirium. He was soon quite well.

CASE 8.-Mrs. —- aged thirty-five; myopic astigmatism. Two single drops of duboisin solution were applied to the right eye. After waiting half an hour she felt uncomfortably giddy, and had difficulty in walking quite straight. There was no dryness of throat. After examination she rested for an hour; but was still giddy when she left. On her way home she felt as if she did not know where she was going, and on that and several succeeding days her head felt vacant, and she found herself not understanding or not hearing what people said. She is tall, pale, nervous, and not in strong health.

\section{CITY OF LONDON LUNATIC ASYLUM.}

CASE OF CARCINOMA OF RIGHT BREAST IN A MAN. (Under the care of Mr. Whitfield Perkins.)

ABouT eighteen months ago, a hard, lobulated, painless swelling was noticed in the right breast of a man, aged forty-nine, an inmate for thirteen years. After remaining thus for many weeks, it suddenly enlarged, softened, and fluctuated. A free incision was made, and eight or ten ounces of pus were evacuated, but the wound never healed. The mass grew hard and vascular, puckering and infiltrating the skin, retracting the nipple, and exuding a sanious discharge from a small ulcerated surface. The axillary glands were not involved; there was no cachexia. The man appeared in robust health, and on the morning he was operated on was scrubbing the floor until the moment he was called away.

The operation was performed on May 6 th. When fully under the influence of chloroform, an incision was made round the tumour, well outside the limit of the involved skin. The tumour was cleanly and entirely detached and removed; some eight or ten spouting points were twisted, and two large jetting ones were ligatured. The wound was cleaned and dressed antiseptically. During the night fol. lowing the operation the patient tore off the dressings, and considerable venous hæmorrhage resulted, but subsequently he made a rapid recovery, without an untoward symptom. Thirteen days after the operation he was able to get up, and shortly afterwards resumed his ordinary industrious avocations.

The tumour was a medullary cancer, and is now in the museum of Guy's Hospital.

\section{H I T CHIN I N F IRMARY.} REMARKABLE ACCIDENTS.

(Under the care of Dr. O. H. Foster.)

CASE 1. Fall from a Cart; the left Extemal Iliac Artery torn asunder; Death.-On June 10th, J. P-—, aged sixty-seven, was driving a one-horse waggon at a foot pace down hill; he was seated on a small cask of beer in the waggon on the off side. The near side wheels ran up the bank and the waggon upset. J.P_fell into the road (clear of the waggon and horse) on to his left side, which was probably accounted for by the cask twisting round as he fell. He was slightly stunned by the fall, butrecovered consciousness almost immediately; he found himself unable to stand and was taken in a cart a distance of about a mile to the infirmary. Happening to be in the building at the time, Dr. Foster saw him as he was being put to bed; he was quite conscious, but his appearance was extremely bloodless. He said he was only shaken, and expressed a wish to go home, a distance of eight miles; but he was advised to stop in the infirmary for a few hours to recover from the shock he had sustained. $\mathrm{He}$ had a slight contusion on the left temple; he moved his various limbs to prove that he was only shaken. His clothes not having as yet been removed, his body was not examined at the time for bruises, but orders were given that he should be kept in bed with hot bottles to his feet, and have beeftea, brandy, \&c. While the nurse was undressing him, she noticed some subcutaneous extravasation of blood in the left groin, and the patient complained of great coldness in the left leg; he took beef-tea, brandy, icc., and seemed fairly comfortable, but gradually sank and died about six hours after admission.

The necropsy was performed next morning. There were marked evidences of extravasation of blood in the left groin, lower part of abdomen, buttock, and scrotum. On careful examination it was found that the left external iliac artery had been completely snapped across, just above Poupart's ligament, and that the surrounding tissues were infiltrated with blood, the scrotum being distended with blood to a considerable extent. No other injuries, visceral or otherwise, could be discovered, except a slight abrasion on the left temple. The spleen was preternaturally small.

Remarks by Dr. FosTER. - It seems strange that a man with so severe an injury should have lived as long as seven hours afterwards, and that at the time I saw him-namely, about half an hour after the accident-he should have had no symptom (though at the time quite conscious) to direet my attention to the nature of the injury. Supposing the exact nature of the injury to have been diagnosed, would one have been justified in any attempt to secure the two ends of the ruptured artery, or would any attempt to do so only have hastened death?

CAsE 2. Wound with an Axe through the external Malleolus and into the Astragalus; Recovery.-On May 5th, C. $\mathrm{D} \longrightarrow$, aged twenty-three, a strong healthy man, was conversing with a woodman who was felling a tree with an axe (using his axe at the time "backhanded"). C. Dinadvertently advanced his right leg in the way of the axe, and received the whole force of the stroke on his outer ankle. He fell to the ground bleeding profusely. The woodman, after tying a pocket-handkerchief round the wound, went for assistance, leaving him alone in the wood for more than half an hour. He was then taken in a cart a distance of six miles to the infirmary, arriving there in a very exhausted condition. The dispenser at the infirmary had the forethought to adjust an Esmarch's elastic bandage round the patient's thigh before removing him from the cart, thereby probably saving his life. Dr. Foster saw him about half an hour after admission, and found that the skin and soft parts (tendons, \&c.) had been divided transversely by a clean-cut wound about four inches long, the outer malleolus being cut quite through, and there being a deep cleft into the body of the astragalus; the anterior tibial and peroneal arteries were divided. Both ends of these arteries were tied. The limb was placed on a "Paget splint," with a swing cradle, and lint soaked in carbolised oil was placed over the wound; it was not deemed advisable to bring the edges of the wound together.

The patient made favourable progress; the ligatures came away in due course; the wound granulated slowly. There was some slight burrowing of matter, more particularly just below the inner malleolus, the matter probably making its way between the shaft of the tibia and the tendo Achillis. This matter was let out by a free incision, and a drainage-tube was inserted. After the first few days the original wound was dressed with "red lotion" (sulphate of zinc and tincture of lavender). Occasionally, when required, for a day or two at a time, a drainage-tube was inserted into the wound. On June 25th a small, irregular piece of bone made its way out of the original wound, which was then slowly closing up. There was every prospect of the patient having a useful leg.

\section{NURSES' TRAINING HOME, GLASGOW.} ORTHOP \&DIC CASES.

(Under the care of Mr. J. CRAwFond RENTON.)

CASE 1. Double Genu Valgum.-D. K-, aged ten, was admitted on October 1st, 1878, affected with knock-knees, both legs forming an angle of $35^{\circ}$ with the thighs, the distance between the heels when the patient was lying down being twenty inches.

On Oct. 7th, assisted by Drs. Lyon and Wallace Anderson, Mr. Renton divided the femur and tibia in the right limb, using the chisel to accomplish this in part, according to the plan recommended by Dr. McEwen. The limb having been 